\title{
Cutaneous T cell Lymphoma (Mycosis Fungoides)
}

\author{
Gull Mohamad Bhat, D.M.,' Hussain Mir, M.D., ${ }^{2}$ Qazi Mohamad Iqbal ${ }^{3}$
}

Departments of 'Medical Oncology, ${ }^{2}$ Internal Medicine and ${ }^{3}$ Community Medicine, Sher-i-Kashmir Institute of Medical Sciences Srinagar

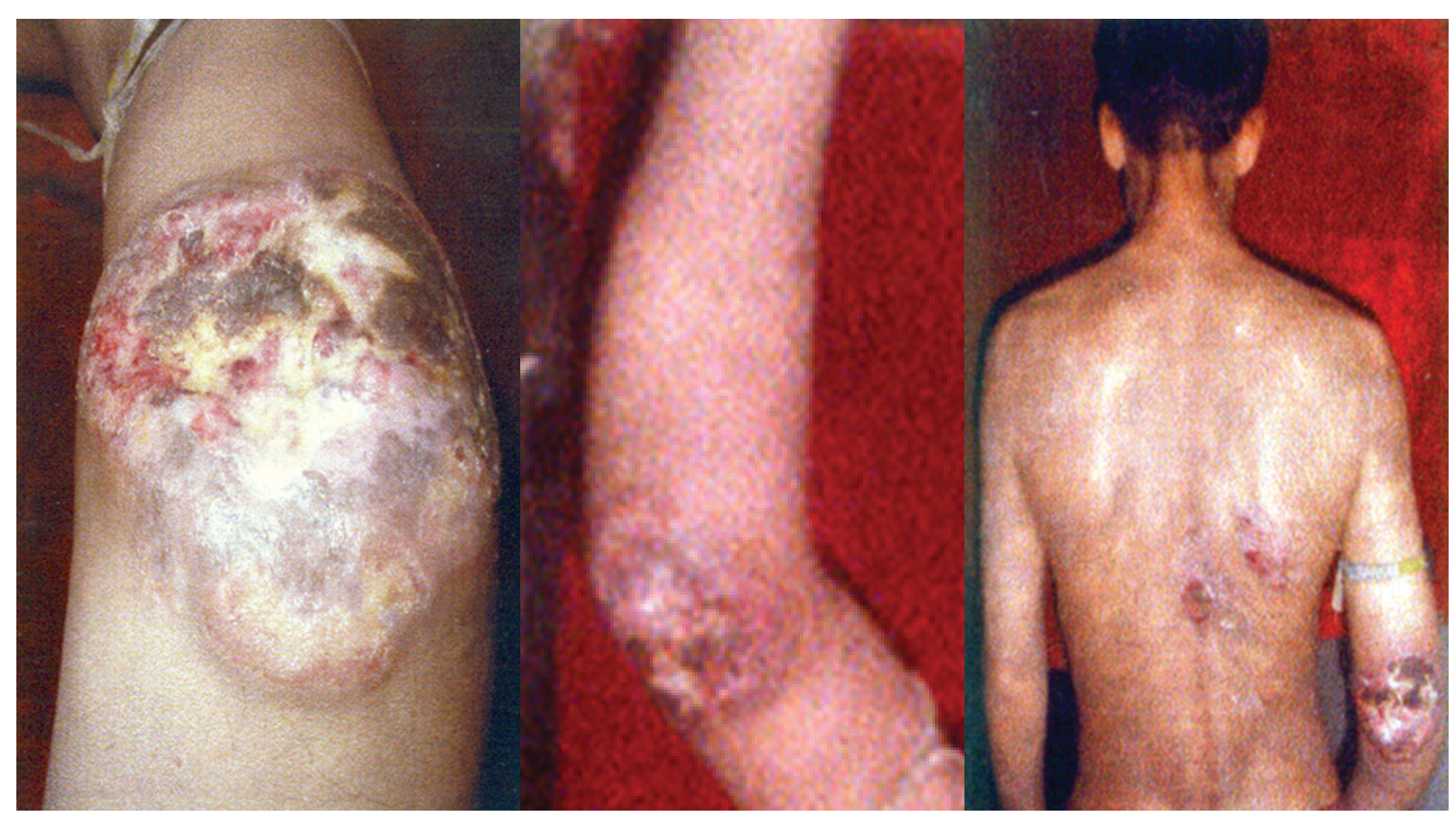

Figures showing ulceronodular lesions in an advanced case of 'Mycosis Fungoides'

Correspondence and reprint requests to:

Dr. Gull Mohamad Bhat

Additional Professor

Department of Medical Oncology

Sher-i-Kashmir Institute of Medical Sciences, Soura,Srinagar,

19001 1, Post Bag 27, Tel: 91 -194-2435825

Drgull81250@yahoo.com
An adult male presented with history of long standing scaly cutaneous lesions, progressed to multiple ulceronodular lesions on back of arm, front of thigh as shown in figure. Histopathology of lesion revealed non-Hodgkins lymphoma(CD4 +v)-Mycosis Fungoides His TNM stage was stage III-T3N1M0. Patient needed systemic multiagent chemotherapy to palliate his advanced disease. 